\title{
LA QUIMÉRICA DICOTOMÍA ENTRE DERECHOS INDIVIDUALES Y SOCIALES*
}

\author{
THE CHIMERIC DICHOTOMY BETWEEN INDIVIDUAL \\ AND SOCIAL RIGHTS \\ LA CHIMÉRIQUE DICHOTOMIE ENTRE LES DROITS \\ INDIVIDUELS ET SOCIAUX
}

\section{Verónica Lidia MARTínEZ MARTÍNEZ ${ }^{* *}$}

\begin{abstract}
RESUMEN: En una primera parte, a partir de las corrientes liberal y socialista, el presente artículo analiza los aspectos de universalidad, onerosidad, justiciabilidad y obligatoriedad que han servido de pilares para sustentar la dicotomía entre derechos individuales y sociales, así como la endeble superioridad de los primeros sobre los segundos. En la segunda parte se aborda la problemática que presentan los derechos económicos, sociales y culturales en México.
\end{abstract}

Palabras clave: derechos sociales, derechos individuales, universalidad, onerosidad, justiciabilidad.

ABSTRACT: From the liberal and socialist currents in a first part, this article analyzes the aspects of universality, onerous, justiciability and enforcement that have served as pillars to support the dichotomy between individual and social rights as well as the weak superiority the former over the latter. In the second part analyzes the problems posed by economic, social and cultural rights in Mexico.

Keywords: social rights, individual rights, universality, onerous, justiciability. 2016.

Recibido el 24 de mayo de 2016 y aceptado para su publicación el 14 de septiembre de

** Especialista en derecho social y maestra en derecho, grados obtenidos en la División de Estudios de Posgrado de la Facultad de Derecho de la UNAM. Miembro de la Academia Mexicana de Derecho de la Seguridad Social. 
RÉSUMÉ: Des courants libéraux et socialistes dans une première partie, cet article analyse les aspects de l'universalité, onéreux, justiciabilité et de l'application qui ont servi de piliers pour soutenir la dichotomie entre les droits individuels et sociaux, ainsi que la supériorité faible du premier sur le second. Dans la deuxième partie analyse les problèmes posés par les droits économiques, sociaux et culturels au Mexique.

Mots-clés: droits individuels, droits sociaux, universalité, onéreux, justiciabilité.

SUMARIO: I. Repercusiones del liberalismo y del socialismo en los derechos humanos. II. Derechos sociales y derechos individuales. III. Problemática que presentan los derechos económicos, sociales y culturales. IV. Bibliografía.

\section{REPERCUSIONES DEL LIBERALISMO Y DEL SOCIALISMO EN LOS DERECHOS HUMANOS}

\section{L}

a más conocida y usada clasificación de los derechos humanos es la que los agrupa por generaciones. Dentro de la primera generación se han agrupado a los derechos civiles y a los políticos (DCP), al ser producto del liberalismo en comunión con el movimiento neoliberal, cuyas principales fuentes se encuentran en la Escuela Austriaca de Economía, la Escuela de Chicago, la Escuela de Virginia de Elección Pública, el pensamiento de Robert Nozick y la Escuela anarco-libertaria o anarco-capitalista.

En cambio, los derechos económicos, sociales y culturales —en adelante DESC - abrevan de las diversas corrientes socialistas —utópico, de Estado, científico, cristiano_ - aunadas a las ideas comunitaristas sostenidas en los trabajos de Walzer, Sandel y MacIntyre.

Así, tenemos que la equivoca tipología de los derechos humanos principalmente se ha sustentado en las ideas filosóficas y políticas vigentes en cada momento histórico. Es bajo esta luz que los derechos de primera generación, como producto del individualismo liberal, hacen referencia al hombre como 
concepto, sustancia y fin, ${ }^{1}$ del que se pueden predicar determinados atributos que constituyen los bienes a tutelar por los derechos humanos, en tanto son necesarios a la condición de persona y encarnan su dignidad. ${ }^{2}$

El liberalismo convierte al individuo en un ente autosuficiente, inviolable ${ }^{3}$ y emancipado con derechos que — al ser innatos y anteriores a la sociedadrequieren del poder del Leviatán para que los respete, garantice y evite su transgresión. En esta concepción, influenciada por el naturalismo de corte racional e idealista, los DCP son auténticos derechos subjetivos que poseen una dimensión negativa, por lo cual es inadmisible la derivación de posiciones de derecho fundamental que tuvieran como objeto una prestación a cargo del Estado. ${ }^{4}$

Para los liberales, el poder público a través de las leyes positivas — guiadas por la ley-madre que dicta: no hagas nunca daño a tu prójimo— debe garantizar el disfrute y goce de los derechos individuales, con especial atención en la libertad y la propiedad. ${ }^{5}$ Bajo la idea de que la ley no era enemiga de la libertad, aquellos ordenamientos que inoportunamente estorbaban la libertad de los ciudadanos, se consideraban contrarios al fin de cualquier sociedad, y debían ser abolidos ${ }^{6}$ de inmediato, al existir de acuerdo con la corriente fisiócrata, la supremacía de la sociedad civil sobre el poder público que deviene en una radical escisión entre tales entes, y favorece la distinción entre derecho público y derecho privado, así como entre sus fuentes supremas: la ley y el

1 Para Kant, los individuos son fines y no simplemente medios, por lo tanto no pueden ser sacrificados o usados, sin su consentimiento, para alcanzar otros fines. Véase Kant, Immanuel, Cimentación para la metafísica de las costumbres, México, Aguilar, 1973, p. 111.

2 Martínez Bullé-Goyri, Víctor Manuel, "La construcción jurídica de los derechos humanos económicos, sociales y culturales en México”, en Orcí Gándara, Luis y Martínez Bullé-Goyri, Víctor Manuel (coords.), Los derechos humanos económicos, sociales y culturales. Hacia una cultura del bienestar, México, Comisión Nacional de Derechos Humanos, 2009, p. 25.

3 El principio kantiano de inviolabilidad de la persona es retomado por Nozick, siendo el derecho y el Estado los medios creados para servir a los intereses de los individuos. Véase Nozick, Robert, Anarquia, Estado y utopia, trad. de Rolando Tamayo Salmorán, México, Fondo de Cultura Económica, 2001, p. 43.

4 Bernal Pulido, Carlos, El principio de proporcionalidad y los derechos fundamentales, Bogotá, Universidad Externado de Colombia, 2014, p. 455.

5 Hayek, F. A., Liberalismo; disponible en http:// wmw7.uc.cl/icp/ revista/pdf/ rev42/arb.pdf (fecha de consulta: 15 de abril de 2016).

6 Sieyés, Emmanuel J., Ensayo sobre los privilegios, trad. de José Rico Godoy, México, UNAM, 1989, p. 145. 
contrato, respectivamente, por lo cual es objeto del primer tipo de derecho velar por el interés público, pero sin intervenir en los ámbitos económico y social, de los cuales se ocupa el derecho privado.

Las principales objeciones a la interferencia del Estado se apoyan en las siguientes razones: ${ }^{7}$

- Es probable que lo que se va a hacer, pueda hacerse mejor por los individuos que por el gobierno. Nadie hay tan adecuado para llevar a cabo cualquier asunto o para determinar cómo o por quién debe efectuarse, como los personalmente interesados.

- Cuando los individuos se encargan de sus propios asuntos se refuerzan sus facultades activas de ejercitar su criterio y familiarizarse con los conocimientos de los asuntos que tengan que tratar. Los individuos son los mejores jueces de sus propios intereses.

- Es un gran mal aumentar innecesariamente la fuerza del Estado. Todo acto que acrecienta las funciones estatales provoca que su influencia sobre los temores y esperanzas se difunda más extensamente, y convierte cada vez más la parte activa y ambiciosa del pueblo en dependiente del gobierno o en un partido que trata de convertirse en gobierno.

Lo anterior pone de manifiesto que es prioritaria la desaparición del Estado intervencionista que entorpece la producción de bienes y servicios. Se trata de que el aparato estatal asuma el papel de vigilante y sólo se mezcle en los asuntos privados de sus gobernados, cuando un individuo transgreda los derechos de otro ser humano, o como mucho, sólo ha de ocuparse de aquellas funciones económicas que por no ser lucrativas son despreciadas ${ }^{8}$ por los particulares, confiado en que la mano invisible del mercado provocaría un creciente bienestar social para todos los individuos.

Sin embargo, al imperar la menor intervención del Estado en atención a la fórmula francesa laissez faire, laissez passer, se desencadenó la desprotección y exclusión para aquellos que no podían acceder a un buen empleo, por lo que la historia demostró que esta tesis estaba equivocada, pues las grandes crisis

\footnotetext{
7 Stuart Mill, John, Sobre la libertad, 3a. ed., México, Gernika, 1996, pp. 172-174

8 Contreras Peláez, Francisco J., Derechos sociales: teoría e ideología, Madrid, Tecnos, 1994, p. 17.
} 
económicas del capitalismo evidenciaron que el modelo liberal burgués no sólo engendraba injusticia social, sino que era el causante de los desequilibrios sociales.

La solución a esas marcadas desigualdades sociales, desde la estructura política, se dio con la transformación del viejo modelo del Estado liberal mínimo en un Estado social, que al constituirse como un ente legislativo y administrativo, asume entre sus responsabilidades la redistribución de la riqueza y el deber de garantizar a todos los individuos mínimos de subsistencia material y bienestar con la necesaria restricción del libre juego de las individualidades.

De acuerdo con Jens Alber, las principales justificaciones del surgimiento del Estado social pueden dividirse en pluralistas y marxistas, y éstas a su vez, se subdividen en funcionalistas y conflictualistas. ${ }^{9}$

Para la corriente pluralista funcional, el Estado social surge como una respuesta a necesidades objetivas suscitadas por la modernización socio-económica, es decir, en la medida en que el sistema económico va evolucionando y los trabajadores se especializan buscan emigrar a las ciudades, por lo que el sistema político debe responder a través de la generación de los contenidos característicos del Estado social. Como exponentes de esta teoría sobresalen Wilensky, Lebeaux y Forsthoff. ${ }^{10}$

El punto de vista pluralista de corte conflictual — sostenido por Marshall y Heimann - afirma que el Estado social es el producto de la presión política de los sectores más desfavorecidos, posible gracias a la ampliación del sufragio y al ejercicio de los derechos de reunión y asociación que posibilitan una acción más eficaz de la clase obrera a través de los sindicatos ${ }^{11}$ y partidos políticos de izquierda.

Por su parte, la corriente marxista-funcionalista — representada por Müller, Offe y O'Connor- establece que el surgimiento del Estado social se debe a ciertas exigencias estructurales del capitalismo maduro. Entre esas exigencias prevalece la necesidad de asegurar el mantenimiento del Estado de derecho, la reproducción de la fuerza de trabajo e integrar al movimiento obrero dentro del sistema, abortando la amenaza de acudir a la vida revolu-

\footnotetext{
9 Citado en Contreras Peláez, Francisco José, Defensa del Estado social, Sevilla, Universidad de Sevilla, 1996, p. 12.

10 Idem.

11 Idem.
} 
cionaria o al control del nacionalsocialismo, por lo que al Estado social se le concibe como un componente más del sistema, es decir, como una consecuencia del mantenimiento de la contradicción capitalista en una fase nueva de ese modo de producción. ${ }^{12}$

A los anteriores factores se adicionan la modificación del concepto de pobreza, y en la medida en que se impone una visión de ésta como problema estructural de hondas raíces sociales y económicas ${ }^{13}$ se genera el ocaso de la apatía estatal en los ámbitos económico y social.

Finalmente, la visión marxista conflictualista, patrocinada por Korpi, Ginsburgh y Gough, establece que el Estado social es el resultado de una serie de conquistas del proletariado, y constituye un episodio intermedio en la lucha de clases. ${ }^{14}$

En atención a lo anterior, tenemos que las variadas perspectivas de origen marxista se reparten entre la explicación del Estado social como exigencia del proceso de acumulación del capitalismo, y aquellas otras que lo sitúan en clave multicausal dependiente, tanto del desarrollo del conflicto social básico, como de los requerimientos económicos que servirán para evidenciar la contradicción entre acumulación-legitimación, y erigir al Estado social como paliativo para mediar tal contradicción a través de una política presupuestaria destinada a financiar la reproducción y condiciones de la fuerza de trabajo, ${ }^{15}$ debido a que los problemas sociales del Estado ante las crisis económicas en el continente americano, y en Europa se agudizan porque no presta asistencia y cuenta con poco margen presupuestario para superarlas.

A pesar de la diversidad de corrientes que discrepan respecto al origen del Estado social, este modelo es producto de la convergencia de tres condiciones básicas: ${ }^{16}$

\footnotetext{
12 Cabo Martín, Carlos de, La crisis del Estado social, Barcelona, PPU, 1985, pp. 20 y ss.

13 Añón Roig, María José y García Añón, José, Lecciones de derechos sociales, Valencia, Tirant lo Blanch, 2002, p. 51.

14 Contreras Peláez, Francisco José, op. cit., p. 12.

15 Cascajo Castro, José Luis, "La configuración del Estado social en la Constitución Española”, en Cámara Villar, Gregorio y Cano Bueso, Juan (coord.), Estudios sobre el Estado social. El Estado social y la comunidad autónoma andaluza, Madrid, 1993, p. 53.

16 Carbonell, Miguel, La garantía de los derechos sociales en la teoría de Luigi Ferrajoli. Documento de trabajo, México, UNAM, Instituto de Investigaciones Jurídicas, 2004, p. 4.
} 
- El individuo es incapaz de satisfacer por sí solo, o con la ayuda de su entorno social más inmediato, sus necesidades básicas.

- Surgen riesgos sociales que no pueden ser enfrentados por las vías tradicionales, basadas en la responsabilidad individual.

- Se desarrolla la convicción social de que el Estado debe asumir la responsabilidad de garantizar a todos los ciudadanos un mínimo de bienestar, si el Estado no cumpliera con esa obligación, se pondría en duda su legitimidad.

Es así que al deberse el surgimiento del Estado social a su papel providencial como nivelador de las desigualdades derivadas de la libre contratación y la negociación en un ámbito de libertad, una de sus principales tareas es conjugar el crecimiento económico y tener una cierta sensibilidad social, dinamismo económico ${ }^{17}$ con el acompañamiento de los derechos sociales. Esto significa que el poder público ha de hacerse cargo de la prestación de servicios, tales como educación, sanidad, asistencia social, empleo pleno, seguridad social, que en el modelo liberal eran asunto de la iniciativa privada o de las organizaciones benéficas.

Esta nueva faceta del Estado — resultado de la estatalización de la sociedad y de la socialización del Estado-_ ${ }^{18}$ constituye el más claro ejemplo del Estado intervencionista o, en palabras de Norberto Bobbio, del Estado máximo o total, ${ }^{19}$ porque no deja espacio alguno fuera de sí mismo, provocando con ello que la esfera pública prevalezca sobre la privada, y surja la noción de servicio social, cuya finalidad no es otra que la de atender las cada vez mayores demandas de bienestar por parte de la ciudadanía. ${ }^{20}$

Debido a que la teoría de los derechos fundamentales en el Estado social se basa en el concepto de necesidad a que alude Tugendhant ${ }^{21}$ y en la visión del individuo como un ente necesitado, a los DESC se les reconoce como

\footnotetext{
17 Cascajo Castro, José Luis, op. cit., p. 42.

18 Bernal Pulido, Carlos, op. cit., p. 442.

19 Bobbio, Norberto, Estado, gobierno y sociedad. Por una teoría general de la politica, México, 2014, p. 29.

20 Ruipérez, Javier, "Estado social versus "aldea global", Anuario da Facultade de Dereito da Universidade da Coruña, La Coruña, núm. 8, 2004, p. 820.

21 Tugendhant, Ernst, Lecciones sobre ética, trad. de Luis Román Rabanaque, Barcelona, Gedisa, 1997.
} 
derechos positivos, de crédito o prestacionales de carácter oneroso a cargo de los poderes públicos o de quien resulte obligado, cuyo contenido obligacional se constriñe en proporcionar servicios que, en principio, el sujeto titular podría obtener en el mercado si tuviera medios suficientes para ello. ${ }^{22}$

Precisamente es en aras de la justicia social, vinculada a las relaciones reguladas por el derecho social, que en la Constitución, como producto de la autonomía social, ${ }^{23}$ se regulan materias que en el Estado liberal se encomendaban a las leyes ordinarias, o eran reglamentadas bajo la figura del contrato, tal es el caso de la estructura y funcionamiento de la actividad económica, que al codificarse en el texto constitucional dio lugar a la denominación helleriana de Constitución económica, además de que la inclusión de normas de naturaleza social constituye una de las notas más definidas de la etapa denominada como constitucionalismo social. ${ }^{24}$

De hecho, bajo los valores de la equidad, solidaridad, justicia distributiva e igualdad material o sustancial que implican derechos no a defenderse ante cualquier discriminación normativa, sino a gozar de un régimen jurídico diferenciado o desigual en atención precisamente a una desigualdad real que trata de ser limitada o superada, ${ }^{25}$ en el Estado socialista proliferan las normas jurídicas ad boc, que si bien se producen para atender necesidades inmediatas, son derogadas ante el surgimiento de nuevas necesidades.

Lo anterior, en palabras de Zagrebelsky, se ha denominado como pulverización o particularismo de la ley, precisamente ${ }^{26}$ por existir un abandono de los principios de generalidad y abstracción — como fuente de inspiración de la noción de ley en el Estado decimonónico o Estado legalista de derecho-y proliferar un sinnúmero de leyes-acto ${ }^{27}$ que se muestran propicias a lo que

\footnotetext{
22 Alexy, Robert, Teoría de los derechos fundamentales, Madrid, Centro de Estudios Políticos y Constitucionales, 2002, p. 482.

23 Zagrebelsky, Gustavo, La ley y su justicia. Tres capitulos de justicia constitucional, trad. de Adela Mora Cañada y Manuel Martínez Neira, Madrid, Trotta, 2008, p. 193.

24 Vanossi, Jorge Reinaldo A., El Estado de derecho en el constitucionalismo social, Buenos Aires, Eudeba, 2000, p. 537.

25 Prieto Sanchís, Luis, "Los derechos sociales y el principio de igualdad sustancial", en Carbonell, Miguel et al. (comp.), Derechos sociales y derechos de las minorías, México, Porrúa-UNAM, 2001, pp. 25 y 26.

26 Zagrebelsky, Gustavo, El derecho dúctil. Ley, derechos, justicia, trad. de Marina Gascón, Madrid, Trotta, 2011, p. 37.

27 Pisarello, Gerardo, "El Estado social como Estado constitucional: mejores garantías,
} 
Ferrajoli califica como espacios de legalidad atenuada ${ }^{28}$ y decisionismo administrativo en un entorno de componentes discrecionales, paternalistas y clientelistas propicios para que se fortalezca la falaz concepción de los derechos sociales como principios de naturaleza esencialmente política, o bien meros privilegios en favor de aquellos sectores en condiciones de acceder al mercado laboral formal, ${ }^{29}$ con un carácter programático, particular e injusticiable que contrasta con la universalidad y justiciabilidad de los DCP.

\section{DERECHOS SOCIALES Y DERECHOS INDIVIDUALES}

La referida contraposición de las vertientes liberal y socialista posibilita la caracterización de los derechos humanos en la tabla que puede observarse en la página siguiente, para después proceder al análisis de los caracteres de la tabla mencionada.

\section{Universalidad}

El gran invento jurídico-político de la modernidad reside, precisamente, en haber ampliado la titularidad de los derechos humanos a todos los hombres por el mero hecho de su nacimiento. En este sentido, la universalidad de todos los derechos humanos — reconocida en la Declaración adoptada en Viena el 25 de junio de 1993 - significa intrinsecalidad con relación al hombre en cuanto ser humano, ${ }^{30}$ sin que sea necesario título específico para adquirirlos. Sencillamente la universalidad de los derechos humanos proviene de nuestra común humanidad, y de su relación umbilical con la dignidad del ser humano.

más democracia", en Abramovich, Víctor et al., Derechos sociales: instrucciones de uso, México, Fontamara, 2003, p. 29.

28 Ferrajoli, Luigi, Derecho y razón. Teoría del garantismo penal, México, Trotta, 1997, p. 63.

29 Ferrajoli, Luigi, "Estado social y Estado de derecho", en Abramovich, Víctor et al. (coord.), Derechos sociales: instrucciones de uso, México, Fontamara, 2003, p. 7.

30 Diemer, A., "Los derechos humanos desde una perspectiva europea", en Diemer, A. et al., Los fundamentos filosóficos de los derechos humanos, trad. de Graziella Baravalle, Barcelona, Ediciones del Serbal, 1985, p. 109. 
Tabla

\begin{tabular}{|c|c|c|c|}
\hline \multicolumn{2}{|c|}{ Pensamiento liberal } & \multicolumn{2}{|c|}{ Pensamiento socialista } \\
\hline DCP & DESC & DCP & DESC \\
\hline Universales & $\begin{array}{l}\text { Específicos de los } \\
\text { grupos vulnerables }\end{array}$ & $\begin{array}{l}\text { Derechos } \\
\text { específicos de los } \\
\text { burgueses }\end{array}$ & Universales \\
\hline Derechos baratos & $\begin{array}{l}\text { Derechos } \\
\text { onerosos }\end{array}$ & $\begin{array}{l}\text { Derechos } \\
\text { onerosos }\end{array}$ & $\begin{array}{l}\text { Derechos } \\
\text { onerosos }\end{array}$ \\
\hline $\begin{array}{l}\text { Derechos } \\
\text { subjetivos }\end{array}$ & $\begin{array}{l}\text { Normas } \\
\text { programáticas }\end{array}$ & $\begin{array}{l}\text { Derechos } \\
\text { subjetivos }\end{array}$ & $\begin{array}{l}\text { Derechos } \\
\text { subjetivos }\end{array}$ \\
\hline Absolutos & Relativos & $\begin{array}{l}\text { Derechos } \\
\text { formales ante } \\
\text { la carencia de } \\
\text { autonomía } \\
\text { económica }\end{array}$ & $\begin{array}{l}\text { Derechos } \\
\text { sustantivos }\end{array}$ \\
\hline $\begin{array}{l}\text { Naturales o } \\
\text { preestatales }\end{array}$ & $\begin{array}{l}\text { Derivan de la } \\
\text { comunidad }\end{array}$ & $\begin{array}{l}\text { Derechos } \\
\text { derivados }\end{array}$ & $\begin{array}{l}\text { Primarios. } \\
\text { Satisfechos, } \\
\text { permiten el } \\
\text { disfrute de los } \\
\text { DCP }\end{array}$ \\
\hline $\begin{array}{l}\text { Definitivos, en } \\
\text { cuanto su mero } \\
\text { enunciado define } \\
\text { su contenido }\end{array}$ & $\begin{array}{l}\text { Progresivos. } \\
\text { Su eficacia } \\
\text { depende de la } \\
\text { instrumentación } \\
\text { de medios } \\
\text { costosos a cargo } \\
\text { del Estado }\end{array}$ & $\begin{array}{l}\text { Su disfrute sólo } \\
\text { se daba a través } \\
\text { de los derechos } \\
\text { sociales }\end{array}$ & $\begin{array}{l}\text { Inmediatos. } \\
\text { Deben ser } \\
\text { directamente } \\
\text { satisfechos por } \\
\text { la organización } \\
\text { política }\end{array}$ \\
\hline $\begin{array}{l}\text { Involucran } \\
\text { obligaciones } \\
\text { negativas } \\
\end{array}$ & $\begin{array}{l}\text { Involucran } \\
\text { obligaciones } \\
\text { positivas }\end{array}$ & $\begin{array}{l}\text { Obligaciones } \\
\text { positivas }\end{array}$ & $\begin{array}{l}\text { Pluralidad de } \\
\text { obligaciones }\end{array}$ \\
\hline $\begin{array}{l}\text { Derechos } \\
\text { justiciables }\end{array}$ & Injusticiabilidad & $\begin{array}{l}\text { Derechos } \\
\text { justiciables }\end{array}$ & $\begin{array}{l}\text { Derechos } \\
\text { justiciables }\end{array}$ \\
\hline
\end{tabular}


$\mathrm{Al}$ abordar el tema de la universalidad resulta obligada la referencia a dos procesos históricos de los derechos humanos: la generalización y la especificación. El primero, en lo básico, supone la extensión de la titularidad de los derechos a sujetos y colectivos que no los poseían, ${ }^{31}$ por lo que de atender a este aspecto tenemos que los derechos individuales nacieron sin la nota de universalidad, en la realidad su titularidad correspondía a la burguesía, por lo cual es el mérito del proceso de generalización, la compaginación de la idea de igualdad formal con la universalidad, lo que posibilita la extensión de la titularidad de los derechos a todos los sujetos. ${ }^{32}$

Si la universalidad de los derechos consistiera en que el derecho en cuestión debe ser actualmente disfrutado por todos los seres humanos, sea cual fuere la ocasión en que se encuentren, entonces algunos derechos individuales clásicos no son ni han sido nunca universales, y en consecuencia no serían derechos humanos, ${ }^{33}$ como acontece en los derechos de propiedad y participación política que se confieren a los ciudadanos de un Estado.

Evidentemente que es deseable la generalización de los DESC, sin embargo, el que ciertos derechos se prediquen de los seres humanos que se encuentran en situaciones de vulnerabilidad, o que su disfrute dependa de una cierta configuración ocasional, no es un óbice para negar su carácter universal.

Básicamente la universalidad como producto de un exacerbado individualismo, parte de una concepción abstracta del ser humano, a la que posteriormente dota de contenido concreto, donde se privilegia el dato de independencia y autonomía del individuo. Es decir, como lo apunta Encarnación Fernández se transita de la universalidad abstracta a la universalidad concreta $^{34}$ de la que se deriva el segundo proceso histórico: la especificación o concreción de los derechos.

Precisamente la especificación — que Bobbio destacara — como un avance del historicismo sobre el racionalismo que se produce en relación con los

\footnotetext{
31 Asís, Rafael de, Cuestiones de derechos, Colombia, Universalidad Externado de Colombia, 2005, p. 112.

32 Idem.

33 Hierro, Liborio, "Los derechos económico-sociales y el principio de igualdad en la teoría de los derechos de Robert Alexy”, en Alexy, Robert et al., Derechos sociales y ponderación, México, Fontamara, 2013, p. 174.

34 Citada en Ramírez García, Hugo Saúl y Pallares Yabur, Pedro de Jesús, Derechos humanos, México, Oxford, 2011, p. 65.
} 
titulares de los derechos y con los contenidos de los derechos, ${ }^{35}$ no supone atribuirles a las personas pertenecientes a estos grupos derechos distintos, sino únicamente concretar algunas exigencias especificas de los derechos humanos básicas en su situación particular.

La especificación en los contenidos de los derechos se caracteriza por la aparición de nuevos derechos tales como el medio ambiente, el desarrollo o la paz. ${ }^{36}$ Por su parte, la especificación, en lo referente a los titulares, consiste en asignar derechos a sujetos específicos o que se encuentran en determinadas circunstancias, como sucede con los derechos laborales, los derechos sindicales, los derechos de las personas de la tercera edad o con capacidades especiales.

Por tanto, es en este segundo tipo de relación en donde la universalidad reside en términos de generalización, ${ }^{37}$ al extenderse a todos los individuos pertenecientes a un determinado conjunto o grupo ${ }^{38}$ definido por el derecho sin excepción, no porque ese conjunto necesariamente se identifique con la humanidad. ${ }^{39}$ Mientras que la especificación se relaciona con supuestas situaciones de desventaja respecto a determinados bienes que otros colectivos tienen satisfechos o protegidos a través de ciertos instrumentos. ${ }^{40}$

\section{Onerosidad}

Los derechos humanos, al requerir de acciones positivas para asegurar su cumplimiento, consecuentemente ostentan el atributo de la onerosidad. Basta con observar que, en la realidad, los derechos de libertad y propiedad requieren de instaurar garantías de seguridad confiadas a las funciones de policía, ${ }^{41}$ que hacen inevitable la erogación de recursos con cargo al erario. Incluso los

\footnotetext{
35 Peces Barba, Gregorio, Curso de derechos fundamentales. Teoría general, Madrid, Universidad Carlos III de Madrid, Boletín Oficial del Estado, 1999, p. 180.

36 Asís, Rafael de, op. cit., p. 104.

37 Ibidem, p. 116.

38 Lema Añón, Carlos, Salud, justicia, derechos. El derecho a la salud como derecho social, Madrid, Dykinson, 2009, p. 175.

39 Ibidem, p. 175.

40 Asís, Rafael de, op. cit., p. 116.

41 Ferrajoli, Luigi, Principia iuris. Teoría de la democracia, trad. de Perfecto Andrés Ibáñez et al., Madrid, Trotta, 2011, pp. 66 y 67.
} 
derechos al debido proceso y los derechos políticos —entre los que destaca el financiamiento de los partidos políticos, la organización de las campañas electorales y de las operaciones de voto- exigen para la esfera pública el otorgamiento de prestaciones positivas que, en la mayoría de los países, representan una parte importante del presupuesto de egresos.

Empero, al conferir preponderancia al carácter prestacional de los DESC, se ha intentado, por una parte, negar la universalidad de este tipo de derechos, al hacerles depender de manera primordial de las circunstancias económicas, y por otra parte, ha sido el pilar para sustentar su injusticiabilidad.

La denominada condicionante económica ${ }^{42}$ reside en que la eficacia de los derechos sociales se encuentra supeditada a la "reserva de lo económicamente posible," entendida como gradualidad como dimensión lógica necesaria de la concretización de los derechos sociales, teniendo en cuenta, sobre todo, los límites financieros. ${ }^{43}$ Sin embargo, tal contrariedad pierde fuerza al haber puesto de relieve el Comité de Derechos Económicos, Sociales y Culturales que, aunque se demuestre que los recursos disponibles son insuficientes, sigue en pie la obligación de que el Estado parte de asegurar el disfrute más amplio posible de los derechos pertinentes, dadas las circunstancias reinantes. ${ }^{44}$

$\mathrm{Y}$ es que, si bien la onerosidad prevalece como constante en todos los derechos humanos, ellos son factores o presupuestos del crecimiento económico. Por tanto, sus violaciones no sólo producen una degradación de las condiciones de vida de las personas, ${ }^{45}$ sino sobre todo, en el caso de los derechos sociales, su incumplimiento provoca la destrucción de energías aunada a una reducción de la productividad y la riqueza.

\section{Justiciabilidad}

La otra tesis que importa analizar como criterio diferenciador entre derechos individuales y derechos sociales es la tutela jurisdiccional. Frente a la in-

\footnotetext{
42 Abramovich, Víctor y Courtis, Christian, Los derechos sociales como derechos exigibles, Madrid, Trotta, 2013, p. 32.

43 Ansuátegui Roig, Francisco Javier, "Argumentos para una teoría de los derechos sociales", Revista de Derecho del Estado, núm. 14, julio de 2010, p. 62.

44 Comité de Derechos Económicos, Sociales y Culturales; disponible en http:/ / wnw1.umn. edu/humanrts/gencomm/Sepcomm3.htm (fecha de consulta: 12 de mayo de 2016).

45 Ferrajoli, Luigi, Principia iuris..., cit., p. 68.
} 
negable tutela de los derechos civiles y políticos, la mayoría de los iusfilósofos ha sostenido que el principal problema de los DESC es su injusticiabilidad o imperfecta justiciabilidad.

La justiciabilidad o accionabilidad entendida como la posibilidad de reclamar ante un juez o tribunal de justicia el cumplimiento al menos de algunas de las obligaciones que se derivan del derecho ${ }^{46}$ presenta las siguientes objeciones:

La primera objeción contra la justiciabilidad de los DESC se dirige contra la imprecisión en su contenido. Respecto de este punto es necesario señalar que un serio obstáculo en el ámbito jurídico se encuentra en la existencia de un lenguaje pseudonormativo, lo que implica que la mayoría de la terminología jurídica se recoge del lenguaje común o normal que utilizamos en la vida cotidiana para comunicarnos y, al mismo tiempo, forman parte del lenguaje especializado que utilizan los juristas.

A este respecto, Pollock y Maitland sostienen que buena parte de la dificultad, en lo que atañe a la terminología jurídica, se origina en el hecho de que muchas de nuestras palabras sólo eran aplicables originariamente a cosas físicas; ${ }^{47}$ de modo que su uso en conexión con relaciones jurídicas es, hablando estrictamente, figurativo o ficticio, ${ }^{48}$ por lo cual es necesario - como lo plantea el realismo genovés - alejarse de la tendencia de trasladar consideraciones del lenguaje natural hacia el lenguaje jurídico, pues se trata de esferas diferentes, y del hecho de que el lenguaje (punto y aparte) funcione de una manera, no se sigue que necesariamente el lenguaje jurídico funcione sólo de esa manera. ${ }^{49}$

A la anterior medida debiera sumarse la necesaria definición del contenido mínimo esencial o contenido básico mínimo de los derechos humanos, pues a pesar de que todos los derechos presentan "zonas de penumbra", todos

46 Abramovich, Víctor y Courtis, Christian, "Apuntes sobre la exigibilidad judicial de los derechos sociales," en Abramovich, Víctor et al. (coord.), Derechos sociales: instrucciones de uso, México, Fontamara, 2003, p. 61.

47 Citado en Hohfeld, W. N., Conceptos jurídicos fundamentales, 5a. ed., trad. de Genaro R. Carrió, México, Fontamara, 2001, p. 36.

48 Idem.

49 Bouvier, Hernán G., "Lenguaje y teoría del derecho. Tensiones en una variante del realismo jurídico", Isonomía. Revista de Teoría y Filosofía del Derecho, México, núm. 35, octubre de 2011, p. 51. 
cuentan con un núcleo de certeza indisponible e irreductible del que pueden extraerse contenidos y deberes básicos para los poderes públicos.

El núcleo de certeza, naturalmente viene determinado por convenciones lingüísticas y prácticas hermenéuticas que pueden evolucionar y modificarse a partir de nuevos desarrollos interpretativos, ${ }^{50} \mathrm{y}$ de los principios de razonabilidad y proporcionalidad que en comunión con los Principios de Limburgo, las Directrices de Maastricht, las 100 Reglas de Brasilia y las Observaciones Generales del Comité de Derechos Económicos, Sociales y Culturales, abren la posibilidad de definir con mayor precisión y claridad las obligaciones de los Estados contenidas en el Pacto Internacional de DESC y así asegurar su aplicación y cumplimiento.

La segunda objeción a la justiciabilidad de los DESC se refiere a las limitadas competencias técnicas de los jueces para resolver cuestiones complejas con elevadas consecuencias presupuestarias. ${ }^{51}$ Este punto, en correlación con los considerables costes financieros que se tienen que erogar para asegurar el cumplimiento de los DESC, encuentra su principal apoyo en la división de poderes que — como base fundamental del Estado democrático de derecho- impide a los tribunales decidir sobre la política presupuestaria.

Contra esta objeción de orden funcional es necesario puntualizar dos aspectos importantes. El primero de ellos tiene que ver con la superación de la tesis antifederalista que plantea la estricta separación de poderes para dar paso a la concepción dominante sostenida por Madison que propone un sistema de "frenos y contrapesos" 52 basado en la capacidad de interacción e interferencia de un poder sobre otro, bajo la idea de que cada rama del gobierno cuenta con las armas suficientes y necesarias para resistir los seguros embates de los demás. ${ }^{53}$

Las relaciones entre los órganos del Estado son innegables y necesarias ante la elaboración de normas a través del derecho de veto o en uso de su facul-

\footnotetext{
50 Pisarello, Gerardo, Los derechos sociales y sus garantias. Elementos para una reconstrucción, Madrid, Trotta, 2007, p. 67.

51 Pisarello, Gerardo, “El Estado social...”, cit., p. 36.

52 Hamilton, A. et al., El Federalista, trad. de Gustavo Velasco, México, Fondo de Cultura Económica, 1994.

53 Gargarella, Roberto, “Justicia dialógica y derechos sociales", en Espinoza de los Monteros, Javier y Ordóñez, Jorge (coords.), Los derechos sociales en el Estado constitucional, México, Tirant lo Blanch, 2013, p. 114.
} 
tad reglamentaria; la aprobación del Poder Legislativo a los nombramientos que realiza el Ejecutivo; la facultad judicial que ejercer el Poder Legislativo en la declaratoria de procedencia o juicio político; las funciones legislativas que realizan los tribunales ante la creación de normas de organización y funcionamiento, así como su intervención en una gama considerable de cuestiones que tienen consecuencias importantes en el ámbito económico, del cual es un claro ejemplo la resolución de los juicios administrativos, de seguridad social, mercantiles, los laborales, entre los que destacan los casos de huelga y los conflictos colectivos de naturaleza económica.

Es ante tal panorama que el Comité de Derechos Económicos, Sociales y Culturales ha enfatizado que la adopción de una clasificación rígida de los DESC que los sitúe, por definición, fuera del ámbito de los tribunales sería arbitraria e incompatible con el principio de indivisibilidad e interdependencia de los derechos humanos, además de reducir drásticamente la capacidad de los tribunales para proteger los derechos de los grupos más vulnerables y desfavorecidos de la sociedad. ${ }^{54}$

Por su parte, la tercera objeción a la accionabilidad ${ }^{55}$ de los DESC deriva de su consideración como normas programáticas impositivas de objetivos o tareas estatales a realizar por los órganos políticos en aras de un beneficio colectivo que lleva a su estigmatización como derechos imperfectos, ${ }^{56}$ derechos de papel $^{57}$ o derechos disminuidos, pero no como derechos subjetivos.

El sustento de esta refutación es la equivoca identificación — que hacen autores como Kelsen, Reine Rechtslehre y Atria- del derecho con sus garantías. La mayoría de los doctrinarios reconoce que en la existencia de un derecho subjetivo es necesaria la presencia de tres elementos fundamentales, los cuales son:

54 Observación General 9, punto 10, del Comité de Derechos Económicos, Sociales y Culturales; disponible en https:// wmw.escr-net.org/docs/i/428708 (fecha de consulta: 9 de mayo de 2016).

55 Habermas habla de la accionabilidad de los derechos como la posibilidad de reclamar judicialmente su cumplimiento. Véase Habermas, Jürgen, Facticidad y validez. Sobre el derecho y el Estado democrático de derecho en términos de teoría del discurso, 2a. ed., México, Trotta, 2000, p. 188.

56 Barcellona Pietro, "Los sujetos y las normas", en Oliva, Enrique (comp.), Problemas de legitimación del Estado social, Madrid, Trotta, 1991, p. 34.

57 Guastini, Riccardo, Distinguiendo. Estudios de teoría y metateoría del derecho, Barcelona, Gedisa, 1999, pp. 185-189. 
- El derecho subjetivo como necesariamente derivado de una norma jurídica. Ante todo, en el caso de los derechos sociales, su dimensión jurídica no se proyecta frente a la ley, como ocurre en el caso de las libertades, sino que comienza a partir de la ley. ${ }^{58}$

- El simultáneo deber u obligación jurídica que corresponde a otra persona para hacer o dejar de hacer algo prescrito en la norma.

- A estos dos elementos se adiciona la denominada posición jurídica consistente en un poder jurídico para la consecución de intereses propios reconocidos al sujeto. ${ }^{59}$ En las posiciones jurídicas existen relaciones tridimensionales en las que un sujeto activo (el titular) ostenta un derecho subjetivo a que el sujeto pasivo (el legislador y la administración) despliegue una determinada conducta que constituye el objeto de su deber. ${ }^{60}$

En tanto que la garantía consiste en aquellos mecanismos que sirven para asegurar la efectividad de un derecho subjetivo. Divididas en garantías primarias y secundarias, las primeras constituyen límites y vínculos normativos, o sea prohibiciones y obligaciones, formales y sustanciales, impuestas, en tutela de los derechos, al ejercicio de cualquier poder ${ }^{61}$ que ante su fracaso o insuficiencia posibilitan la aplicación de una garantía secundaria, cuya inexistencia de ninguna manera invalida el derecho subjetivo, por el contrario se asume como una indebida laguna que los poderes públicos internos e internacionales tienen la obligación de colmar. ${ }^{62}$

Finalmente, la cuarta objeción importante en contra de la justiciabilidad de los DESC se refiere al reclamo de este tipo de derechos sociales en conexión con otros derechos judicialmente exigibles ${ }^{63}$ como son los derechos civiles

\footnotetext{
58 Bernal Pulido, Carlos, op. cit., p. 462.

59 Arango, Rodolfo, El concepto de derechos sociales fundamentales, Colombia, Legis, 2005, p. 9.

60 Bernal Pulido, Carlos, El derecho de los derechos. Escritos sobre la aplicación de los derechos fundamentales, Colombia, Universidad Externado de Colombia, 2005, p. 317.

61 Memoria del Seminario "Garantismo y derechos humanos de la política criminal en México", Centro de Investigaciones Jurídico-Políticas de la División de Estudios de Posgrado de la Universidad Autónoma de Tlaxcala, diciembre de 2010, p. 178.

62 Ferrajoli, Luigi, Derechos y garantías. La ley del más débil, Madrid, Trotta, 2010, p. 63.

63 García Morales, Aniza, "La justiciabilidad como garantía de los derechos sociales”, en Pisarello, Gerardo (ed.), Los derechos sociales como derechos justiciables: potencialidades y limites, Albacete, Bomarzo, 2007, pp. 30 y 31.
} 
y políticos —especialmente a través de los derechos al debido proceso, ${ }^{64} \mathrm{a}$ la propiedad — ${ }^{65} \mathrm{O}$ a partir de principios y valores, ${ }^{66}$ dentro de los cuales sobresalen la igualdad, libertad, dignidad de la persona, justicia social, el libre desarrollo de la personalidad, la obligación de la progresividad, ${ }^{67}$ y las prohibiciones de discriminación ${ }^{68}$ y regresividad.

Empero, ante las más variadas estrategias de justiciabilidad directa que abarca mecanismos nacionales e internacionales para el reclamo de los DESC, más que una debilidad, el litigio estratégico o justiciabilidad indirecta se constituye como un paliativo para superar las objeciones a la justiciabilidad de los derechos sociales y una vía que permite emplear los mecanismos de exigibilidad de los derechos civiles, ${ }^{69}$ lo que evidencia la interdependencia e indivisibilidad de los derechos humanos reconocida por la Corte Interameri-

64 A manera de ejemplo, pueden apuntarse los asuntos siguientes: caso Deumeland vs. Alemania; caso Feldbrugge vs. Países Bajos; caso Schuler-Zgraggen vs. Suiza; caso Salerno vs. Italia; caso Salesi vs. Italia; caso Schouten y Meldrum vs. Países Bajos y caso Mennitto vs. Italia. Véase Tribunal Europeo de Derechos Humanos; disponible en http://hudoc.echr.coe.int/eng?i=00157420\#\{ "item id": ["001-57420"] \} (fecha de consulta: 11 de mayo de 2016).

65 Caso Múller y Austria; caso Anqinas vs. Chipre; caso Willis vs. Reino Unido; caso Wessels-Berger voat vs. Países Bajos; caso Buchen vs. República Checa; caso Aunola vs. Finlandia; caso Van den Bouwhuijsen y Schuring vs. Países Bajos; caso Plotnikovy vs. Rusia; caso Kjartan Asmundsson vs. Islandia; caso Makarova vs. Rusia. Véase Tribunal Europeo de Derechos Humanos; disponible en bttp:/ / budoc.echr.coe. int/ eng?i=001-57420\#\{ "itemid": "001-57420"]\} (fecha de consulta: 11 de mayo de 2016). El caso Cinco pensionistas vs. Perú. Véase Corte Interamericana de Derechos Humanos; disponible en http://mmw.corteidh.or.cr/docs/casos/articulos/seriec_198_esp.pdf (fecha de consulta: 7 de mayo de 2016).

66 Pisarello, Gerardo, "La justiciabilidad de los derechos sociales en el sistema constitucional español”, en Pisarello, Gerardo (ed.), Los derechos sociales como derechos justiciables: potencialidades y limites, Albacete, Bomarzo, 2007, pp. 57 y 58.

67 Se pueden referir como ejemplos los siguientes: caso Milton García Fajardo y otros vs. Nicaragua; caso Jorge Odir Miranda Cortezy otros vs. El Salvador y el caso Jesús Manuel Naranjo Cárdenas y otros (Jubilados de la Empresa Venezolana de Aviación Viasa) vs. Venezuela.

68 Caso Gaygusuz vs. Austria; Caso Kona Poirrez vs. Francia; Caso Buchen vs. República Checa; Caso Zwaan de Vries vs. Países Bajos, por citar algunos ejemplos. Véase Tribunal Europeo de Derechos Humanos; disponible en http:// hudoc.echr.coe.int/eng? $i=001-57420 \#\{$ "itemid":["001-57420"]\} (fecha de consulta: 11 de mayo de 2016).

69 Caso Acevedo Buendía y otros vs. Perú. Véase Corte Interamericana de Derechos Humanos en http://mmm.corteidh.or.cr/docs/casos/articulos/seriec_198_esp.pdf (fecha de consulta: 7 de mayo de 2016). 
cana de Derechos Humanos, ${ }^{70}$ el Tribunal Europeo de Derechos Humanos, ${ }^{71}$ el Comité de Derechos Económicos, Sociales y Culturales, y la Comisión Africana ${ }^{72}$ cuya tipificación se encuentra en la Declaración Universal de Derechos Humanos, la Declaración de Teherán, los Preámbulos del Pacto Internacional de Derechos Económicos, Sociales y Culturales, y del Pacto Internacional de Derechos Civiles y Políticos, la Declaración de Viena, así como en el Protocolo Adicional a la Convención Americana sobre Derechos Humanos en Materia de Derechos Económicos, Sociales y Culturales.

\section{Aspecto obligacional}

Otro de los mitológicos criterios que distingue a los DCP de los DESC es el que reconoce que el primer tipo de derechos genera deberes de abstención a los Estados, mientras que los derechos económicos, sociales y culturales implican toda una gama de actuaciones positivas financiadas por el aparato estatal con recursos públicos.

El reduccionismo de la anterior distinción se derrumba ante la estructura compleja que presentan todos los derechos humanos que requieren necesariamente de acciones positivas y negativas, lo que posibilita su identificación como "derechos-racimo", es decir, se trata de complejos de obligaciones de diverso tipo. ${ }^{73}$

Varios de los derechos civiles y políticos, como ocurre con la organización de los servicios de administración de justicia, los derechos políticos, de propiedad y de seguridad jurídica, no pueden ejercerse ni alcanzar su plenitud sin una prestación positiva del Estado.

70 Idem. Además del caso María del Carmen Suárez Peralta vs Ecuador en file:/ / C:/ Users/Ad ministrador/Downloads/CasoSuarezPeralta_Ecuador_EPFRC\%20(2).htm (fecha de consulta: 7 de abril de 2016).

71 Caso Airey vs. Irlanda. Véase Tribunal Europeo de Derechos Humanos, en http:/ / budoc. echr.coe.int/ eng? $i=001-57420 \#\{$ "itemid": "001-57420"]\} (fecha de consulta: 11 de mayo de 2016).

72 El Comité de Derechos Económicos, Sociales y Culturales y la Comisión Africana reconocen la interdependencia e indivisibilidad de los derechos en los casos Danning vs. Países Bajos y Malawi African Association vs. Mauritania, respectivamente.

73 Laporta, Francisco, "Los derechos sociales y su protección jurídica: introducción al problema”, en Díaz, Elías, Constitución y derechos fundamentales, Madrid, Centro de Estudios Políticos y Constitucionales, 2004. 
Cosa análoga sucede con los DESC, que incluyen derechos prestacionales y derechos negativos, lo cual, como apunta Ingo Wolfgang dependerá de la naturaleza de la posición jurídico-subjetiva reconocida al titular del derecho. ${ }^{74}$ Así, tenemos que mientras determinados derechos sociales, como el de educación, vivienda, salud y seguridad social involucran acciones positivas y negativas a cargo del legislador y la administración; por el contrario, existen otros derechos que requieren de abstenciones por parte del Estado, como ocurre en el caso de los derechos de sindicalización y huelga.

En esta tesitura, dentro de las obligaciones específicas a cargo del Estado, el Comité de DESC ha distinguido a las siguientes: ${ }^{75}$

- Obligaciones de respeto. Imponen al Estado un deber de abstenerse de obstaculizar el goce de los derechos económicos, sociales y culturales. Las obligaciones de este tipo presentan una dimensión objetiva y subjetiva. ${ }^{76}$ Desde un punto de vista objetivo implica que las medidas legales que afecten instituciones y servicios públicos en materia, por ejemplo, de educación, asistencia sanitaria, seguridad social o vivienda, respeten siempre el núcleo esencial que, en un contexto dado, identifica dichas instituciones, quedando prohibida toda regulación que suponga su aniquilamiento o su velada desnaturalización. El punto de vista subjetivo, por su parte, comporta la consideración de los derechos sociales no sólo como expectativas de prestaciones, esto es, como derechos positivos, sino también como derechos negativos que obligan al legislador y a la administración a no privar a las personas de recursos básicos que éstas hayan obtenido, sin arbitrariedad, por sí mismas, de terceros o del propio Estado.

- Obligaciones de protección. Su contenido está referido a la prevención de violaciones de los derechos humanos por parte de los poderes públicos y privados.

74 Wolfgang Sarlet, Ingo, "Los derechos sociales en el constitucionalismo contemporáneo: algunos problemas y desafíos", en Presno Linera, Miguel Ángel y Wolfgang Sarlet, Ingo (coords.), Los derechos sociales como instrumento de emancipación, Navarra, Aranzadi, 2010, p. 48.

75 Observaciones generales 12, 13, 16, 18, 19 y 21 del Comité de Derechos Económicos, Sociales y Culturales; disponible en https:// mmm.escr-net.org/docs/i/428708 (fecha de consulta: 4 de mayo de 2016).

76 Pisarello, Gerardo, 'El Estado social...”, cit., pp. 36 y 37. 
- Obligaciones de satisfacción. Comprenden deberes de promoción y garantía. Las obligaciones de promoción ${ }^{77}$ exigen que el Estado adopte medidas dirigidas a la realización y efectividad de los DESC, lo que involucra actuaciones legislativas de promoción diferenciada y actuaciones legislativas de promoción universal. La primera clase de acciones se encuentran dirigidas a garantizar ciertos bienes y recursos a grupos concretos en especial situación de vulnerabilidad. En cambio, las actuaciones de promoción universal consisten en la asignación de ciertos bienes y recursos —educación, asistencia sanitaria-a todas las personas. ${ }^{78}$

En el caso de las obligaciones de garantía, tienen por objeto remediar las violaciones a los derechos humanos directamente imputables al Estado, y aquellas ofensas a los bienes que son objeto de los mismos derechos, imputables a particulares. La garantía no se limita a la investigación y atribución de la responsabilidad correspondiente al agente de la lesión, sino involucra la reparación integral de los daños causados. ${ }^{79}$

Conforme a las Directrices de Maastricht, las obligaciones de respetar, proteger y cumplir incluyen elementos de obligación de conducta y de obligación de resultado. El deber de conducta exige acciones racionalmente concebidas con el propósito de asegurar el ejercicio de un derecho específico. Mientras que la obligación de resultado requiere que los Estados cumplan objetivos concretos que satisfagan una norma sustantiva precisa. ${ }^{80}$

Adicionalmente a este tipo de deberes específicos se suman obligaciones genéricas de cumplimiento inmediato y obligacionales adicionales. Como parte del primer tipo de obligaciones se encuentran la prohibición de discriminación, la adopción de medidas inmediatas y los deberes correlativos

77 Observación general 12 del Comité de Derechos Económicos, Sociales y Culturales; disponible en https:// wmw.escr-net.org/docs/i/428708 (fecha de consulta: 9 de mayo de 2016).

78 Pisarello, Gerardo, “El Estado social...”, cit., pp. 37 y 38.

79 Nikken, Pedro, "La protección de los derechos humanos: haciendo efectiva la progresividad de los derechos económicos, sociales y culturales", Revista del Instituto Interamericano de Derechos Humanos, Caracas, vol. 52, 2010, p. 69.

80 Directrices de Maastricht, en http://ip.aaas.org/escrdocs_sp.nsf/287fccf1bc425ff4852567590 054d44b/77e0aa4feb3691a1852569100068932a?OpenDocument (fecha de consulta: 27 de abril de 2016). 
de progresividad y regresividad. En el caso de las obligaciones adicionales se ubican el acceso a la información y el desarrollo de indicadores.

Es así como los distintos tipos de obligaciones jurídicas, como parte fundamental del concepto de derecho subjetivo, vienen a reiterar el carácter justiciable de los DESC.

\section{PROBLEMÁtiCA QUE PRESENTAN LOS DERECHOS ECONÓMICOS, SOCIALES Y CULTURALES}

Frente a la indivisibilidad e interdependencia de los derechos humanos y la desmentida tesis de la no susceptibilidad de tutela judicial de los DESC ante la experiencia jurídica nacional e internacional, consideramos que en nuestro país, el principal problema que aqueja a este tipo de derechos es la inadecuación de sus garantías secundarias.

En primer lugar, lamentablemente, tenemos que ante las omisiones o lagunas existentes en la normatividad de índole social, se ha recurrido a la indebida aplicación supletoria del derecho civil y mercantil, ${ }^{81}$ cuyos principios rectores son disímbolos a los que prevalecen en el ámbito social.

Básicamente la igualdad, al ser la médula de la justicia conmutativa, que impera en las cuestiones civiles y mercantiles, presupone la existencia de dos personas jurídicamente equiparadas entre sí, ubicadas en un plano de igualdad absoluta. En tanto que la justicia distributiva, que preconiza la igualdad proporcional en el trato dado a diferentes personas, presupone la existencia cuando menos de una persona colocada en un plano superior y que impone cargas o confiere beneficios a dos o más subordinadas a ella. ${ }^{82}$

La justicia distributiva no atiende a la igualdad rei ad rem entre lo dado y lo recibido (igualdad aritmética), sino a la igualdad de proporción (igualdad geométrica). ${ }^{83} \mathrm{Al}$ analizar las bases y relaciones que tienen lugar en la justicia distributiva, Helmut Coing concluye que éstos bien podrían llamarse también

81 Artículo 2o. de la Ley Agraria. En lo no previsto en esta ley, se aplicará supletoriamente la legislación civil federal y, en su caso, mercantil, según la materia de que se trate.

82 Radbruch, Gustav, Introducción a la filosofía del derecho, México, Fondo de Cultura Económica, 1951, pp. 31 y 32.

83 Martínez Pineda, Ángel, El derecho, los valores éticos y la dignidad humana, México, Porrúa, 2000 , p. 36. 
de "la justicia social, teniendo en cuenta la orientación de la comunidad", 84 pues es claro que no puede hacerse justicia igual para seres que son desiguales.

Es en aras de la justicia social vinculada a las relaciones reguladas por el derecho social que se justifica el establecimiento de normas protectoras en favor de los trabajadores, ejidatarios, comuneros, colonos, avecindados, pequeños propietarios, consumidores, socios cooperativistas, asegurados, pensionados y sus beneficiarios, para eliminar o limitar las desigualdades que existen en la realidad, por lo cual es inconveniente la aplicación supletoria del derecho civil y mercantil en aspectos relativos al derecho social.

El derecho social, al tener como fundamentos rectores al hombre, la integración social y la justicia social, no parte de la idea de igualdad de las personas su ideal es buscar una positiva igualdad social y económica- Se trata de un "derecho igualador de las naturales desigualdades y nivelador de las desproporciones que existen entre las personas, en donde la igualdad deja de ser un punto de partida para convertirse en meta o aspiración del orden jurídico". ${ }^{85}$

En virtud de lo anterior, es necesario contar con una normatividad que cumpla con la denominada racionalidad lingüística y procedimental. El primer tipo de racionalidad implica la creación de normas que prescriban de manera sencilla y precisa los contenidos y presupuestos de cada derecho social, 86 para hacerlos asequibles a los grupos vulnerables a los que se dirige, ya que los derechos sólo pueden volverse socialmente eficaces en la medida que sus destinatarios estén informados sobre su existencia, contenido y manera de ejercerlos ante su transgresión.

Por su parte, la racionalidad procedimental implica la instauración, dentro de la normatividad social, de garantías secundarias eficaces y restitutorias de los derechos transgredidos en el menor tiempo posible, que sean acordes con el contenido esencial del derecho social que ha de regular, pues tales presupuestos constituyen la base para la existencia de un Estado social y democrático de derecho.

Los procedimientos son sistemas de reglas y principios para la obtención de un resultado, cuando ese resultado es logrado respetando las reglas y prin-

\footnotetext{
84 Helmut, Coing, Fundamentos de filosofía del derecho, Barcelona, Ariel, 1961, p. 198.

85 González Díaz, Lombardo, El derecho social y la seguridad social integral, México, UNAM, 1978, pp. 49 y 50.

86 Ferrajoli, Luigi, Derecho y rąón..., cit., pp. 917 y 918.
} 
cipios, entonces, desde el aspecto procedimental presenta una característica positiva. Si no es obtenido de esta manera, entonces es defectuoso desde el punto de vista procedimental y, por ello, tiene una característica negativa. ${ }^{87}$

A guisa de ejemplo, tenemos que las principales inconsistencias en la resolución de los conflictos en materia de seguros sociales se deben, en gran medida, a la inexistencia de normas procedimentales en la Ley del Seguro Social y la Ley del ISSSTE que garanticen la interposición, tramitación, resolución y ejecución de este tipo de controversias conforme a su naturaleza, principios y trascendencia dentro del desarrollo de nuestro país.

Equivocadamente hemos recurrido a la legislación laboral, burocrática y fiscal para resolver aisladamente los reclamos en materia de seguridad social, a pesar de que los ámbitos de aplicación de dichos ordenamientos jurídicos no son las relaciones tripartitas que existen entre la institución asegurada, el asegurado y el empleador que involucran elementos objetivos y normativos, prestaciones, principios e instituciones disímiles que sustantiva y procesalmente deben regularse dentro de las leyes de seguridad social.

Lamentablemente, el conocimiento teórico-práctico del derecho laboral que se exige al personal encargado de tramitar y resolver los conflictos individuales de seguridad social es insuficiente para resolver las múltiples y disímiles controversias que plantean los asegurados, pensionados y beneficiarios contra el Instituto Mexicano del Seguro Social, el Instituto del Fondo Nacional de la Vivienda para los Trabajadores y las Administradoras de Fondos para el Retiro a las que debe imponerse las correspondientes obligaciones de garantía. Sobre el particular, Néstor de Buen señala:

Una deformación antigua de los conceptos ha asociado históricamente al derecho del trabajo con el derecho de la seguridad social. Los planes de estudio de las universidades suelen colocarlos juntos, a veces en la compañía comprometedora del derecho burocrático, en una especie de síntesis de lo más importante del derecho social. Por el mismo motivo se ha considerado, por supuesto que sin razón, que ser laboralista lleva en sí mismo el germen de la seguridad social. Nada más falso. ${ }^{88}$

87 Ibidem, p. 457.

88 Buen Lozano, Néstor de, Seguridad social, México, Porrúa, 1995, p. IX. 
Otro aspecto destacable como elemento imprescindible de las nociones de juicio justo y de debido proceso, invocadas en el contexto de procedimientos relativos a los DESC, es el derecho del justiciable a obtener una decisión que ponga fin a la disputa en un plazo razonable. El artículo 8o. de la Convención Americana sobre Derechos Humanos dispone que para garantizar un debido proceso legal se requiere del cumplimiento de los aspectos siguientes:

- Acceso a la justicia sin restricciones personales ni económicas (derecho a ser oído).

- Posibilidad de alegar, probar y argumentar con seguridad jurídica y personal, recurriendo incluso a defensa letrada y de confianza, dentro de un marco de publicidad y oralidad (derecho al proceso).

- Resolución del caso dentro de un tiempo razonable.

- Que la autoridad que resuelva esté legitimada para hacerlo, sea competente, independiente e imparcial (principio de juez natural).

En el caso de los conflictos de seguridad social, los dos últimos elementos se inobservan, pues en primer lugar, la resolución y ejecución de este tipo de controversias queda a cargo de las autoridades laboral y fiscal, sin que ambas tengan competencia en el mandato constitucional. Y, en segundo lugar, el reconocimiento y otorgamiento de sus derechos no sólo conlleva los procedimientos ante la Junta Federal de Conciliación de Arbitraje y la autoridad de amparo, sino un burocrático trámite ante el Instituto Mexicano del Seguro Social para lograr la inclusión en la nómina de pensionados que es necesario para el pago mensual de las prestaciones obtenidas en el juicio laboral, que ante su carácter alimentario, debiera resolverse con prontitud y oportunidad.

En términos análogos, la carencia de recursos eficaces también se hace presente en caso del derecho a alimentación, a pesar de que la Oficina del Alto Comisionado para los Derechos Humanos de la ONU y el Comité de DESC han emitido una serie de recomendaciones y observaciones generales ${ }^{89}$ sobre el carácter básico y fundamental de este derecho para el desarrollo de los pueblos.

89 Observación general 12 del Comité de Derechos Económicos, Sociales y Culturales; disponible en https:// wmw.escr-net.org/docs/i/428708 (fecha de consulta: 9 de mayo de 2016). 
Dentro del sector alimentario, la llegada de las transnacionales con la firma del Tratado de Libre Comercio ha puesto en desventaja a los productos de nuestro país, lo que hace necesaria la instauración de garantías secundarias para garantizar el contenido esencial del derecho a la alimentación, así como la instauración de la instancia jurisdiccional especializada en materia agraria para que funja como garante de este derecho, al que no tienen acceso millones de personas que en nuestro país se encuentran en situación de pobreza extrema.

Empero, y a pesar de la ausencia e inadecuación de las garantías secundarias de los DESC, no por ello pierden fundamentalidad este tipo de derechos, puesto que la efectividad no es una condición de la existencia de la norma sino de su cumplimiento. ${ }^{90}$ Por el contrario, en tales circunstancias existe un incumplimiento, o el cumplimiento defectuoso, por parte de los operadores jurídicos, del mandato implícito de actuación contenido en la normatividad nacional e internacional, ${ }^{91}$ pues no es el derecho el que queda degradado o en calidad de imposible, ${ }^{92}$ sino el poder el que incurre en una actuación desviada o en una omisión que lo deslegitima. ${ }^{93}$

$\mathrm{Y}$ es que provocadas de manera adecuada, las garantías jurisdiccionales pueden introducir un relativo control entre poderes a través de diferentes medidas de presión sobre el legislador y la administración, lo que permite operar como un eficaz elemento de desbloqueo de las constricciones que a dichos ámbitos de decisión les vienen a menudo impuestas por presiones corporativas de diversa índole, evitando de este modo el naufragio tecnocrático

90 Cascajo Castro, José Luis, "Derechos sociales", en Cascajo Castro, José Luis et al. (coord.), Derechos sociales y principios rectores. Actas del IX Congreso de la Asociación de Constitucionalista de España celebrado en Santa Cruz de Tenerife, España, los dias 27 y 28 de enero de 2011, Valencia, Tirant lo Blanch, 2012, p. 35.

91 El Comité de Derechos Económicos, Sociales y Culturales establece que la falta de recursos judiciales adecuados que permitan hacer justiciables los DESC constituye una violación al Pacto Internacional de DESC.

92 Acuña, Juan Manuel, "La jurisdicción constitucional y los derechos imposibles", en Ferrer Mac-Gregor, Eduardo y Zaldívar Lelo de Larrea, Arturo (coord.), La ciencia del derecho procesal constitucional. Estudios en homenaje a Héctor Fix-Zamudio en sus cincuenta años como investigador del derecho, t. IV: Derechos fundamentales y tutela constitucional, México, UNAM-Instituto Mexicano de Derecho Procesal Constitucional-Marcial Pons, 2008, pp. 609-632.

93 Pisarello, Gerardo, Los derechos sociales..., cit., p. 81. 
o simplemente plebiscitario de los deberes políticos en materia de derechos económicos, sociales y culturales. ${ }^{94}$

\section{BIBLIOGRAFÍA}

Abramovich, Víctor y COURTIS, Christian, Los derechos sociales como derechos exigibles, Madrid, Trotta, 2013.

-, "Apuntes sobre la exigibilidad judicial de los derechos sociales", en ABramovich, Víctor et al. (coord.), Derechos sociales: instrucciones de uso, México, Fontamara, 2003.

ACUÑA, Juan Manuel, "La jurisdicción constitucional y los derechos imposibles", en FERrer MAC-Gregor, Eduardo y ZALDívar LELO DE LARREA, Arturo (coord.), La ciencia del derecho procesal constitucional. Estudios en homenaje a Héctor Fix-Zamudio en sus cincuenta años como investigador del derecho, t. IV: Derechos fundamentales y tutela constitucional, México, UNAM-Instituto Mexicano de Derecho Procesal Constitucional-Marcial Pons, 2008.

AleXY, Robert, Teoría de los derechos fundamentales, Madrid, Centro de Estudios Políticos y Constitucionales, 2002.

Ansuátegui Roig, Francisco Javier, "Argumentos para una teoría de los derechos sociales", Revista de Derecho del Estado, núm. 14, julio de 2010.

AÑón Roig, María José y GARCíA AÑón, José, Lecciones de derechos sociales, Valencia, Tirant lo Blanch, 2002.

ARANGO, Rodolfo, El concepto de derechos sociales fundamentales, Colombia, Legis, 2005.

Asís, Rafael de, Cuestiones de derechos, Colombia, Universidad Externado de Colombia, 2005.

BarCellona, Pietro, "Los sujetos y las normas", en Oliva, Enrique (comp.), Problemas de legitimación del Estado social, Madrid, Trotta, 1991.

Bernal Pulido, Carlos, El derecho de los derechos. Escritos sobre la aplicación de los derechos fundamentales, Colombia, Universidad Externado de Colombia, 2005.

94 Habermas, Jürgen, Facticidad y validez..., cit., pp. 337 y 338. 
- El principio de proporcionalidad y los derechos fundamentales, Bogotá, Universidad Externado de Colombia, 2014.

BobBIO, Norberto, Estado, gobierno y sociedad. Por una teoría general de la política, México, 2014.

BOuvier, Hernán G., "Lenguaje y teoría del derecho. Tensiones en una variante del realismo jurídico", Isonomía. Revista de Teoría y Filosofía del Derecho, México, núm. 35, octubre de 2011.

Buen Lozano, Néstor de, Seguridad social, México, Porrúa, 1995.

Cabo Martín, Carlos de, La crisis del Estado social, Barcelona, PPU, 1985.

CARBOnell, Miguel, La garantía de los derechos sociales en la teoría de Luigi Ferrajoli. Documento de trabajo, México, UNAM, Instituto de Investigaciones Jurídicas, 2004.

Cascajo Castro, José Luis, "La configuración del Estado social en la Constitución Española”, en CÁMARA VILLAR, Gregorio y CANO BUESO, Juan (coord.), Estudios sobre el Estado social. El Estado social y la comunidad autónoma andalura, Madrid, 1993.

—_, "Derechos sociales", en CASCAjo CASTRO, José Luis et al. (coord.), Derechos sociales y principios rectores. Actas del IX Congreso de la Asociación de Constitucionalistas de España celebrado en Santa Cruz de Tenerife, España, los días 27 y 28 de enero de 2011, Valencia, Tirant lo Blanch, 2012.

Contreras Peláez, Francisco J., Derechos sociales: teoría e ideología, Madrid, Tecnos, 1994.

—, Defensa del Estado social, Sevilla, Universidad de Sevilla, 1996.

DiEMER, A., "Los derechos humanos desde una perspectiva europea", en Diemer, A. et al., Los fundamentos filosóficos de los derechos humanos, trad. de Graziella Baravalle, Barcelona, Ediciones del Serbal, 1985.

Ferrajoli, Luigi, Derecho y razón. Teoría del garantismo penal, México, Trotta, 1997.

- Derechos y garantías. La ley del más débil, Madrid, Trotta, 2010.

- Principia iuris. Teoría de la democracia, trad. de Perfecto Andrés Ibáñez et al., Madrid, Trotta, 2011. 
GARgarella, Roberto, "Justicia dialógica y derechos sociales", en EsPINOZA DE LOS MONTEROS, Javier y ORDÓÑEZ, Jorge (coords.), Los derechos sociales en el Estado constitucional, México, Tirant lo Blanch, 2013.

GONZÁLEZ DíAz, Lombardo, El derecho social y la seguridad social integral, México, UNAM, 1978.

HABERMAS, Jürgen, Facticidad y validez. Sobre el derecho y el Estado democrático de derecho en términos de teoría del discurso, 2a. ed., México, Trotta, 2000.

Hamilton, A. et al., El federalista, trad. de Gustavo Velasco, México, Fondo de Cultura Económica, 1994.

HAYEK, F. A., Liberalismo; disponible en http://wmw7.uc.cl/icp/revista/pdfl rev42/ar6.pdf (fecha de consulta: 15 de abril de 2016).

Helmut, Coing, Fundamentos de filosofía del derecho, Barcelona, Ariel, 1961.

Hierro, Liborio, "Los derechos económico-sociales y el principio de igualdad en la teoría de los derechos de Robert Alexy", en AlEXY, Robert et al., Derechos sociales y ponderación, México, Fontamara, 2013.

Hohfeld, W. N., Conceptos jurídicos fundamentales, 5a. ed., trad. de Genaro R. Carrió, México, Fontamara, 2001.

LAPORTA, Francisco, "Los derechos sociales y su protección jurídica: introducción al problema", en DíAz, Elías, Constitución y derechos fundamentales, Madrid, Centro de Estudios Políticos y Constitucionales, 2004.

Lema AÑón, Carlos, Salud, justicia, derechos. El derecho a la salud como derecho social, Madrid, Dykinson, 2009.

MARTínez Bullé-GoYRI, Víctor Manuel, "La construcción jurídica de los derechos humanos económicos, sociales y culturales en México”, en OrCí GÁNDARA, Luis y MARTínez BulLÉ-GoYRI, Víctor Manuel (coords.), Los derechos humanos económicos, sociales y culturales. Hacia una cultura del bienestar, México, Comisión Nacional de Derechos Humanos, 2009.

MARTínEZ PINEDA, Ángel, El derecho, los valores éticos y la dignidad humana, México, Porrúa, 2000.

Memoria del Seminario "Garantismo y derechos humanos de la política criminal en México”, Centro de Investigaciones Jurídico-Políticas de la División de Estudios de Posgrado de la Universidad Autónoma de Tlaxcala, diciembre, 2010. 
NiKKEN, Pedro, "La protección de los derechos humanos: haciendo efectiva la progresividad de los derechos económicos, sociales y culturales", Revista del Instituto Interamericano de Derechos Humanos, Caracas, vol. 52, 2010.

PeCes BARBA, Gregorio, Curso de derechos fundamentales. Teoría general, Madrid, Universidad Carlos III de Madrid, Boletín Oficial del Estado, 1999.

PISARELLO, Gerardo, "El Estado social como Estado constitucional: mejores garantías, más democracia”, en ABRAMOVICH, Víctor et al., Derechos sociales: instrucciones de uso, México, Fontamara, 2003.

— Los derechos sociales y sus garantías. Elementos para una reconstrucción, Madrid, Trotta, 2007.

_- "La justiciabilidad de los derechos sociales en el sistema constitucional español", en PISARELLO, Gerardo et al. (ed.), Los derechos sociales como derechos justiciables: potencialidades y límites, Albacete, Bomarzo, 2007.

PRIETO SANCHÍS, Luis, "Los derechos sociales y el principio de igualdad sustancial”, en CARBOnelL, Miguel et al. (comp.), Derechos sociales y derechos de las minorías, México, Porrúa-UNAM, 2001.

RADBRUCH, Gustav, Introducción a la filosofía del derecho, México, Fondo de Cultura Económica, 1951.

Ramírez García, Hugo Saúl y Pallares Yabur, Pedro de Jesús, Derechos humanos, México, Oxford, 2011.

RuiPÉREZ, Javier, "Estado social versus "aldea global”, Anuario da Facultade de Dereito da Universidade da Coruña, La Coruña, núm. 8, 2004.

SIEYÉs, Emmanuel J., Ensayo sobre los privilegios, trad. de José Rico Godoy, México, UNAM, 1989.

STUART MiLl, John, Sobre la libertad, 3a. ed., México, Gernika, 1996.

Tugendhant, Ernst, Lecciones sobre ética, trad. de Luis Román Rabanaque, Barcelona, Gedisa, 1997.

VANOSSI, Jorge Reinaldo A., El Estado de derecho en el constitucionalismo social, Buenos Aires, Eudeba, 2000.

WOLFGANG SARLET, Ingo, "Los derechos sociales en el constitucionalismo contemporáneo: algunos problemas y desafíos", en PRESNO LiNERA, Miguel Ángel y WOLFGANG SARLET, Ingo (coords.), Los derechos sociales como instrumento de emancipación, Navarra, Aranzadi, 2010. 
Esta revista forma parte del acervo de la Biblioteca Jurídica Virtual del Instituto de Investigaciones Jurídicas de la UNAM www.juridicas.unam. $\mathrm{mx}$

ZAGREBELSKY, Gustavo, La ley y su justicia. Tres capitulos de justicia constitucional, trad. de Adela Mora Cañada y Manuel Martínez Neira, Madrid, Trotta, 2008.

, El derecho dúctil. Ley, derechos, justicia, trad. de Marina Gascón, Madrid, Trotta, 2011. \$\$ 